\title{
Pharmacochaperoning of the ER-retained $A_{1}$ adenosine receptor
}

\author{
Justyna Kusek, Christian W Gruber, Christian Nanoff, Michael Freissmuth \\ From 18th Scientific Symposium of the Austrian Pharmacological Society (APHAR). Joint meeting with the \\ Croatian, Serbian and Slovenian Pharmacological Societies. \\ Graz, Austria. 20-21 September 2012
}

\section{Background}

The $\mathrm{A}_{1}$ adenosine receptor is a member of the rhodopsinrelated subfamily of GPCRs. Point mutations in the conserved $\operatorname{NPxxY}(\mathrm{x}) 5,6 \mathrm{~F}$ motif at the junction of helix 7 and the C-terminus disrupt surface targeting of the receptor and result in its intracellular retention. This trafficking arrest can be overcome by addition of receptor ligands (pharmacochaperoning) that stabilize the receptor fold and thus promote surface expression. The mutants serve as a tool to explore a ramification of the retaliatory metabolite complex: hypoxia leads to intracellular accumulation of adenosine (by breakdown of ATP and by inhibition of adenosine kinase). Intracellular and extracellular adenosine levels are in equilibrium because of the action of the equilibrative nucleoside transporters. Extracellular adenosine dampens cellular metabolism by acting on inhibitory $\mathrm{A}_{1}$ adenosine receptors and thus counteracts the impact of hypoxia. If adenosine also pharmacochaperoned $\mathrm{A}_{1}$ adenosine receptors during hypoxia, it would enhance its effectiveness as a protective agent.

\section{Methods}

We created cell lines that stably expressed $A_{1}$ receptor Y288A with either a C-terminal YFP or an N-terminal FLAG-epitope fused to a streptactin peptide. These cell lines were incubated with a combination of inhibitors to test whether manipulations of intracellular adenosine levels increased the accumulation of the receptor. The $A_{1}$ antagonist DPCPX was used as an internal control. To mimic hypoxia, the cells were incubated for 24 hours under $5 \% \mathrm{O}_{2}$ content conditions. Radioligand binding and Western blotting was performed to determine the level of mature, binding competent receptors.

\footnotetext{
* Correspondence: michael.freissmuth@meduniwien.ac.at

Institute of Pharmacology, Center for Physiology and Pharmacology, Medical University of Vienna, 1090 Vienna, Austria
}

C) Biplat Central

(c) 2012 Kusek et al; licensee BioMed Central Ltd. This is an Open Access article distributed under the terms of the Creative Commons Attribution License (http://creativecommons.org/licenses/by/2.0), which permits unrestricted use, distribution, and reproduction in any medium, provided the original work is properly cited.

\section{Results}

Inhibition of adenosine kinase, adenosine deaminase and equilibrative nucleoside transporters enhanced the accumulation of binding competent receptors. The action of these inhibitors was as effective as DPCPX in pharmacochaperoning the receptor. The receptors acquired a mature glycosylation status indicative of export from the ER and delivery to the Golgi, and they reached the cell surface. Moreover, the action of the enzyme inhibitor cocktail could also be elicited by hypoxia.

\section{Conclusions}

Accumulation of intracellular adenosine elicits a pharmacochaperoning effect. Accordingly, the retaliatory metabolite concept may be extended to include a pharmacochaperoning ("physiochaperoning") action of adenosine.

\section{Acknowledgements}

This work was supported by the Austrian Sciences Fund (FWF) and the Medical University of Vienna.

Published: 17 September 2012

doi:10.1186/2050-6511-13-S1-A63

Cite this article as: Kusek et al.: Pharmacochaperoning of the ER-

retained $A_{1}$ adenosine receptor. BMC Pharmacology and Toxicology 2012 13(Suppl 1):A63. 